\title{
Direito Internacional Ambiental e sua interface no contexto constitucional brasileiro
}

\section{Vital José Pessoa Madruga Filho*, Hélder Formiga Fernandes, José Ronildo Souza da Silva}

Universidade Federal da Paraíba. Centro de Ciências Exatas e da Natureza. Programa de Pós-Graduação em Desenvolvimento e Meio Ambiente. Campus I. João Pessoa-PB, Brasil (CEP 58051-900).*E-mail: vitalpessoa@bol.com.br.

Resumo. 0 presente estudo visa a demonstrar que o meio ambiente oferece e dispõe de recursos vitais para a manutenção da vida no Planeta, de modo que é necessário impingir-lhe uma rigorosa tutela jurídica, em face da ação desenfreada do homem que tende a explorar os recursos naturais muito além do que realmente lhe é necessário. Além do mais, a escassez dos recursos naturais associada aos altos níveis da poluição global, impõem nefastos índices de degradação ambiental, cujos efeitos e impactos são suportados em todo o mundo. Em função disto, a comunidade internacional foi instada a se manifestar sobre tal problemática, como forma de prestigiar os princípios inerentes ao desenvolvimento sustentável. Para a elaboração do presente artigo, fizeram-se necessárias consultas bibliográfica e documental, acerca das leis nacionais e internacionais que regem a proteção do meio ambiente, como forma de acrescer aos debates acadêmicos e sociais.

Palavras-chave: Direito Internacional Ambiental; Constituição Federal; Meio Ambiente.

\begin{abstract}
International Environmental Law and its interface in the Brazilian constitutional context. The present study aims to demonstrate that the environment offers and has resources vital to the maintenance of life on the Planet, so that it is necessary to impose a strict legal protection, in the face of the unbridled action of the man who tends to exploit the resources much more than you really need. Furthermore, the scarcity of natural resources associated with high levels of global pollution imposes harmful levels of environmental degradation, whose effects and impacts are supported worldwide. As a result, the international community was urged to express its views on this issue, as a way of respecting the principles inherent in sustainable development. For the elaboration of this article, it was necessary to consult bibliographical and documentary, on the national and international laws that govern the protection of the environment, as a way to add to the academic and social debates.
\end{abstract}

Keywords: International Environmental Law; Federal Constitution; Environment.
Recebido: 06/08/2018

Aceito:

27/08/2018

Publicado:

31/08/2018

Acesso aberto

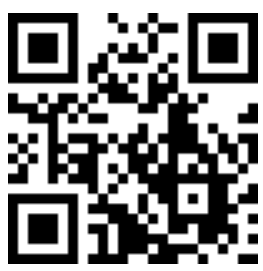

ORCID

나 0000-0002-0351-9807

Vital José Pessoa

Madruga Filho

(1) 0000-0002-0370-0673

Hélder Formiga

Fernandes

(D) 0000-0002-3202-5267

José Ronildo Souza da Silva 


\section{Introdução}

A diversidade ambiental contempla os seres vivos (bióticos), como também os seres inanimados (abióticos). Dessa forma, para conceituar e definir Meio Ambiente é imperioso destacar todas as relações físicas, químicas e biológicas, as quais constituem um complexo sistema natural, que através da ação antrópica, poderão ser categorizados no conceito de meio ambiente artificial. Dessa forma, resta patente que o meio ambiente possui diversas facetas, que sofrem variações de um local para o outro (Sarlet e Fenterseifer, 2011).

A ação humana poderá implicar alterações no meio onde o homem esteja inserido, no entanto, essa intervenção por algumas vezes, pode se mostrar extremamente danosa, gerando impactos imensuráveis ao solo, rios, mares, florestas, animais e até mesmo a si próprio, haja vista que na ocorrência de qualquer desajuste natural, catástrofes como enchentes, extinção de espécies e outras ocorrências fenomenológicas, o homem sente de pronto os efeitos nefastos de tais desequilíbrios (Canotilho, 2010).

0 direcionamento que o homem impõe à natureza, muitas vezes revestese de finalidades econômicas, financeiras, medicinais, científicas dentre outras, variando conforme juízo de oportunidade e conveniência. Ressalte-se que os recursos naturais são finitos em sua essência, de sorte que o homem ainda sobrevive nesse universo, em virtude da existência desses recursos (Canotilho, 2010).

Por tais motivos, diversos cientistas e pesquisadores são motivados a estudar cada vez mais o meio ambiente, como forma de auxiliá-lo na mitigação dos efeitos devastadores da ação antrópica na natureza, além de formas alternativas capazes de conjugar a exploração dos recursos naturais com a necessidade de garantir a proteção do meio ambiente. Desse modo, a tutela ambiental no Brasil não é um direito/ dever do brasileiro nato ou naturalizado, mas um instituto oponível em caráter erga omnes, ou seja, para todos (Canotilho, 2010).

Diante da expressão constitucional que consagra a necessidade da manutenção de um meio ambiente ecologicamente equilibrado, tem-se a consagração de um direito de terceira geração, fulcrado nos ideais fraternos e solidários, enaltecendo e instituindo o princípio ao desenvolvimento sustentável, como forma de garantir um ambiente ávido e saudável para as presentes e futuras gerações (Canotilho, 2010).

\section{Imprescindibilidade do meio ambiente}

A partir dos ideais carreados pelo princípio da dignidade da pessoa humana (art. 10, inciso III, da Constituição Federal), depreende-se que os estudos ambientais favoreceram um efetivo avanço no direito ambiental moderno. É que a partir do aprimoramento conceitual impelido à dignidade humana, inclusive com a máxima ampliação das definições atribuídas a este primoroso princípio fundamental pátrio, tem-se que ressaltar o seu caráter multidimensional, que no caso concreto, alberga a dimensão ecológica (Sarlet e Fenterseifer, 2011).

Diante da forte tendência dos ideais de cunho ecológico, eis que surge uma dita ética incidental à sustentabilidade da vida. Esse novel pensamento, de acordo com Sarlet e Fenterseifer (2011), possibilitou modificações nos conceitos antropocentristas extremamente exacerbado da época, além de favorecer o florescimento de indagações bastante pertinentes à vida na Terra, considerando que até então, vigia a velha máxima de que animais por não serem dotados de racionalidade, poderiam ser utilizados de forma indistinta no que aprouver ao homem.

Como bem aponta Sarlet e Fenterseifer (2011), a Constituição da 
Alemanha de 1949, inspira-se nos conceitos filosóficos de "bases naturais da vida", ao invés de restringi-la à "vida humana" tão somente. De certa forma, essa evolução do pensamento constituinte possibilitou maior inspirações nas leis fundamentais subsequentes, as quais passaram a tutelar as mais variadas formas de vida na terra, sem restrição ao pensamento antropocêntrico, com a finalidade de viabilizar um pretenso equilíbrio ecológico.

0 ponto nodal de toda essa discussão, atinge seu ápice quando se estabelece uma correlação entre os direitos ambientais com os direitos humanos, justificado pelos valores próprios e inerentes do homem para com a natureza, visto que a intervenção humana não se resumo ao meio social em que o mesmo está inserido, mas também ao meio natural, de sorte que a proteção ambiental deve ocorrer não apenas com a finalidade de resguardá-la ao homem, mas sobretudo, como forma de valorizar toda vida na Terra, conforme lição ensinada por Sarlet e Fenterseifer (2011).

Neste condão, resta evidente que a finalidade do constituinte é de ampliar a incidência da dignidade para todos os entes com vida, trazendo de per si, os ideias de respeito e responsabilidade que os seres humanos deverão emoldurar em suas relações com todas as formas de vida existentes no planeta. Nessa mesma linha, Sarlet e Fenterseifer (2011), apregoa o sentido de sensibilização do qual os animais vertebrados são dotados, de forma que suas dores e angústias não poderão ser minimizados em detrimento aos pesares do homem.

Assim, Cavalcanti (2004) estabelece a possível existência de conflito entre desenvolvimento econômico e a preservação da natureza, de modo que um ponto de equilíbrio deve ser ajustado entre esse dualismo, uma vez que o ser humano não pode portar-se como único agente passível de empreender mudanças e impactos no ambiente em que está inserido. Portanto, o autor pretende combater o ideal liberal de crescimento econômico ilimitado, a fim de que pela preservação da natureza e através do equilíbrio relacional entre esses dois vértices, os recursos naturais possam ser explorados e utilizados de forma racional, como forma de assegurar sua eficiência e duração no tempo e no espaço.

Desse modo, a discussão acaba descambando para o campo da bioética, de modo que segundo Diniz e Guilhem (2002), a temática impõe reflexões de cunho moral, no que tange aos estudos relativos à saúde, utilizando-se de animais, cuja permissibilidade científica encontra muitos embates filosóficos.

A razão de tudo isso reside no fato de que, o direito ao meio ambiente ecologicamente equilibrado, perpassa por sua classificação na condição de direito fundamental, de acordo com previsibilidade e deferência constitucional oportunizada ao tema. Desse modo, consoante os efeitos constitucionais e legais atribuídos aos direitos fundamentais, tem-se que o direito ao meio ambiente ecologicamente equilibrado é irrenunciável, inalienável e imprescritível, favorecendo maior cobertura protecionista a esses direitos.

\section{Tutela legal deferida ao meio ambiente}

A existência de atos legais e normativos tendentes à proteção do meio ambiente, necessita do empenho de outros fatores capazes de subsidiar e efetiva e plena eficácia da norma jurídica, como uma séria e comprometida fiscalização das disposições normativas vigentes, como forma de implementar uma aplicação escorreita dos instrumentos legais disponíveis. É que a simples cominação textual é insuficiente para a garantia da eficácia legal, de modo que é imprescindível a incidência de medidas socioeducativas voltados para o fortalecimento e a formação de uma conscientização acerca da necessidade da proteção do meio ambiente. 
Diante da visão instrumental e utilitarista do meio ambiente, Sarlet e Fenterseifer (2011) contrapõem essa dinâmica através dos ditames do antropocentrismo ecológico, de sorte que o meio ambiente necessidade de uma tutela legislativa, com o fito de resgatar os aspectos filosóficos deferidos ao princípio da dignidade da pessoa humana, mesmo que a norma seja direcionada e destinada a seres bióticos e abióticos, considerando que esses entes fazem jus à parcela do princípio dignitário.

Já Souza (2004), apregoa os ideais da teoria antropocêntricaecocêntrica, pelas quais os bens jurídicos ambientais devem sofrer a tutela legal de cunho penal, pois o meio ambiente deve ser visto como um a finalidade em si mesmo, haja vista que a responsabilidade do homem para com a natureza não fica adstrita apenas ao meio ambiente, mas também às futuras gerações.

Considerando as duas correntes supra citadas, há de se inferir uma sutil diferença filosófica entre ambas, uma vez que a teoria antropocêntrica sustenta que a finalidade e o interesse legal reservado ao meio ambiente, funda-se na necessidade de proteger os interesses do homem para com a natureza, de modo que os bens jurídicos ambientais devem ser calcados e pensados sob o critério antropocêntrico. Já a teoria ecocêntrica, coloca os interesses da natureza como uma finalidade em si mesma, independente dos anseios antrópicos pretendidos, de modo que os bens jurídicos ambientais detêm valores próprios, carecedores de per si de proteção legal.

\section{Constituição da República Federativa do Brasil}

Através da análise evolutiva dos textos constitucionais brasileiros, denota-se que suas finalidades básicas era estabelecer as regras do mecanismo de funcionamento estatal e assegurar os direitos dos cidadãos, a fim de evitar o seu perecimento pela atuação do Estado.
Assim, denota-se a prescidibilidade do trato das questões ambientais tratados nas Constituições anteriores à Carta da República de 1988 (Benjamim, 2010).

Para o autor (Benjamim, 2010), com o galopante crescimento da crise ambiental, afetando o planeta em proporções escandalosas, principalmente em decorrência dos efeitos nefastos da poluição do ar e das águas, iniciou-se um movimento proposto por diversos organismos internacionais, com 0 propósito de inferir maiores proteções legais ao meio ambiente, as quais deveriam ser absorvidas por diploma normativo de grande valia no ordenamento jurídico de cada país, como é o exemplo da Constituição.

Dessa forma, Benjamim (2010) sustenta que "o direito ambiental tem aversão ao discurso vazio; é uma disciplina jurídica de resultado, que só se justifica pelo que alcança, concretamente, no quadro social das intervenções degradadoras". Assim, resta claro que as questões afetas ao meio ambiente repudiam uma retórica sofista do tema, exigindo iniciativas que implementem e favoreçam a aplicação das normas ambientais. Portanto, a existência de uma lei constitucional que trate das questões ambientais é de grande valia não só para o ordenamento jurídico contemplado e brindado com tal faceta, mas para toda a sociedade envolvida e submetida à égide legal, já que o meio ambiente contará com um amparo jurídico ditoso e colossal.

No mais, é de se suscitar os inúmeros princípios difundidos por todo o texto constitucional, de sorte que a matéria ambiental está gizada na fora do art. 225 da Carta Magna, pelo qual "todos possuem o direito ao meio ambiente ecologicamente equilibrado garantindo a sadia qualidade de vida, cabendo ao Poder Público $e$ à coletividade o dever de preservá-lo e defende-lo".

Segundo Benjamim (2010), existem seis benefícios materiais e outros cinco de ordem formal decorrentes da positivação constitu- 
cional de normas de cunho ambiental. Assim, para o citado autor, o primeiro benefício material diz respeito a uma prestação negativa, qual seja, de não degradar o meio ambiente, a partir de uma "base do regime de explorabilidade limitada e condicionada". Nesse panorama, resta suscitar que o regramento ambiental são autossuficientes, ou seja, independem de complementação ou suplementação normativa, além de possuir efeitos vinculantes junto ao ordenamento jurídico, sendo consideradas transindividual e atemporal.

Ainda segundo o autor supracitado, outro benefício material, diz respeito aos efeitos da função social da propriedade, além do caráter de ecologização, pelos quais, não obstante a existência e constância dos princípios constitucionais da livre iniciativa e da propriedade privada, é de se salientar a limitação do gozo de tais direitos, através de uma fruição limitada e condicionada, tendente a evitar abusos e possibilitar um melhoramento do controle ambiental, nos termos estatuídos pelos art. 170, inciso VI, c/c art. 186, inciso II, da Constituição da República.

No que diz respeito ao terceiro benefício material, Benjamim (2010) ensina que se trata da "proteção ambiental como direito fundamental", de modo que o texto constitucional toma o meio ambiente em seu expoente, quando o impele a categoria de direito fundamental, cuja sobrelevância se sustenta na medida em que o meio ambiente é matéria de maior interesse para o Poder Público.

Com relação ao quarto benefício, há uma sintonia com os ideais do estado interventor, inspirado no "Welfare State", e traduz a função estatal reguladora e sua legitimação constitucional, na medida em que o Estado assume a incumbência da proteção ambiental, além de absorver o poder punitivo oponível aqueles que desrespeitarem as normas vigentes, distanciando assim, dos ideias inerentes ao Estado Liberal, que exerce pouca função do controle estatal (Benjamim, 2010).

Já o quinto benefício lecionado por Benjamim (2010), preconiza pela redução da discricionariedade estatal, a fim de que o Poder Público possa contar com variadas opções de controle ambiental, com o fito de adotar a menos gravosa para o meio ambiente.

Por último, Benjamim (2010) assevera o sexto benefício material, pelo qual se favorece a ampliação da participação popular nos enfrentamentos de demandas de cunho ambiental, além dos mecanismos de controle oficiais, detidos pelos poderes públicas (executivo, legislativo e judiciário), enaltecendo a responsabilidade social como mecanismo hábil e legítimo para ações de impacto ambiental, possibilitando um melhoramento na malha do poder de polícia.

Feita essas breves colações acerca dos aspectos materiais, decorrentes da positivação de normas de cunho ambiental no texto constitucional, infere-se também a existência de normas de caráter formal, que favorecem a materialização do direito.

Dessa forma, o primeiro benefício formal observado por Benjamim (2010), revela a máxima precedência e importância dos direitos, deveres e princípios ambientais, haja vista que sob o aspecto hierárquico, a norma constitucional dispõe de privilegiada posição na estrutura das leis, de modo que o arcabouço legal de um Estado deve subordinação e adequação aos ditames do texto constitucional.

Já no que é preconizado ao segundo benefício formal, tem-se a segurança normativa, que para Benjamim (2010) decorre da característica de super rigidez da Constituição da República de 1988, emoldurada através de suas cláusulas pétreas, consideradas imutáveis enquanto vigente o texto constitucional. Desse modo, as normas constitucionais impingidas sob esse manto protetor, não são suscetíveis de alteração normativa, 
além do que, mesmo as normas não detentoras do caráter de cláusula pétrea, devem sofrer um rígido processo legislativo de alteração do texto normativo.

No que diz respeito ao quarto benefício formal, Benjamim (2010), estabelece os mecanismos de controle de constitucionalidade da lei, de modo que os diplomas legais e normativos infraconstitucionais devem observância e adequação aos ditames constitucionais. Ressalte-se que o cumprimento dos dispositivos constitucionais, não vinculam apenas os textos normativos infraconstitucionais, mas também a própria atuação do Poder Público e o funcionamento das instituições pátrias, de modo que leis infraconstitucionais e disposições normativas em dissonância com o texto constitucional poderão ser declaradas inconstitucionais, através dos mecanismos do controle de constitucionalidade disponíveis.

0 último benefício de cunho formal, traz consigo o reforço hermenêutico e exegético em favor do meio ambiente relativo às normas infraconstitucionais, de sorte que a previsão normativa e constitucional de normas alusivas ao meio ambiente, possibilita uma revisão geral no arcabouço normativo pátrio, através de uma revisão das leis infraconstitucionais, de modo que a Constituição deve ser observada como verdadeiro paradigma para os operadores do direito e os órgãos públicos que lidam com questões ambientais, além da sociedade em geral (Benjamim, 2010).

Há de se ressaltar a premente importância da positivação de normas de cunho ambiental no texto constitucional, haja vista a disposição de mecanismos próprios de tutela ambiental disponibilizados pelo texto constitucional, como é caso da ação popular, da ação civil pública, com cominações de penalidades civis, criminais e administrativas, como forma de sancionar e responsabilizar as pessoas que eventualmente degradarem o meio ambiente.
Além do mais, a previsão constitucional da tutela ambiental não permite que as causas e questões ambientais distem da morosidade e desídia do Poder Legislativo, que por outro lado, eventual alteração em sua sistemática é de difícil concretização, tendo em vista o caráter rígido no processo de modificação das normas constitucionais.

Todavia, há correntes constitucionalistas que defendem a supressão de algumas matérias contidas no texto constitucional de 1988, a exemplo da proteção deferida ao meio ambiente, sob o argumento de que a Carta Magna serve apenas a existência de poucas normas e de caráter amplo e genérico, defendendo por fim que, o conteúdo ambiental deve ser disciplinado por leis infraconstitucionais, que podem sofrer alterações por processos legislativos menos complexo e dificultoso, conforme pontua Benjamim (2010).

Tal posição é demasiadamente temerária, na medida em que as questões ambientais, tão sensíveis à sociedade hodierna, poderão ser objeto de pressões por parte de grupos econômicos fortíssimos, o que tornaria a demanda ambiental bastante fragilizada em meio a um Parlamento de posições e comportamentos questionáveis.

Não obstante a imprescindibilidade da previsão de normas ambientais no texto constitucional é imperioso destacar o caráter abstrato da regência ambiental, incapaz de reger todos os casos concretos e questões suscitadas cotidianamente, o que força a produção superveniente de leis complementares, capazes de prever metas e sanções às infrações ambientais, oriundas da produção legiferante das casas legislativas, além da absorção dos acordos ou tratados internacionais em que o Brasil é signatário.

\section{Fontes internacionais}

Além da legislação brasileira em vigor, é cediço que o ordenamento jurídico pátrio, cede parcela de força 
normativa a documentos internacionais, tais como: tratados, acordos, convenções e reuniões sob a órbita mundial, oriundos de discussões e debates sobre temas especializados, a exemplo do meio ambiente. Sob o enfoque ambiental, a existência de uma legislação internacional viabiliza e garante $o$ progresso do desenvolvimento sustentável em escala internacional.

Deste modo, uma das primeiras conferências internacionais em que o tema "meio ambiente" foi abordado, ocorreu em Estocolmo, nos idos de 1972. Os efeitos dessa Conferência, a qual fora organizada pelas Nações Unidas, desencadeou o berço e os alicerces do desenvolvimento sustentável, elencando a premente necessidade de cooperação dos países envolvidos, além de manifestar preocupação com os problemas e impactos ambientais presenciados pelo planeta (Le Preste, 2005).

Nesse compasso, no que pertine aos animais, em 1978 houve o advento da Declaração Universal dos Direitos dos Animais, providenciado pela Organização das Nações Unidas para a Educação, a Ciência e a Cultura (Unesco), que positivou inúmeros direitos para os animais considerados irracionais. 0 combate aos maus tratos desferidos contra animais, além da necessidade de proteção contra tratamentos degradantes, sem falar do direito de permanência desses animais no seu ambiente nativo, formou o esteio desse importante documento normativo (Le Preste, 2005).

O Brasil sediou em 1992, importante Conferência Internacional, que ficou conhecido como Rio-92, que trouxe à tona exaustivos debates acerca do desenvolvimento sustentável, com vistas a garantir um modelo econômico capaz de atender e privilegiar a proteção ambiental, reduzindo os alarmantes índices de degradação da natureza, e possibilitando, por conseguinte, benefícios para as gerações vindouras (Thomé, 2012).
A partir do aquecimento global, estudiosos se debruçaram ao estudos das causas que estavam evidenciado 0 famigerado "efeito estufa", de sorte que estabeleceu-se a necessidade de proteção à camada de ozônio, composta de uma camada de gás que envolve a Terra, conforme estudo da World Wide Fund for Nature (WWF), e serve de proteção à incidência dos raios ultravioletas solares, que podem ocasionar diversas patologias à saúde humana e dos animais, a exemplo de queimaduras ou até mesmo câncer de pele, para tanto, a Convenção de Viena para a Proteção da Camada de Ozônio, em 1985, e o Protocolo de Montreal, de 1989, serviram de território para subsidiar e promover as discussões do tema.

Para Thomé (2012), o surgimento do Protocolo de Kyoto, em 1997, teve por escopo propiciar complementação aos ajustes obtidos na Rio-92, de modo que esse protocolo possibilitou ajustes entre os países emissores de gás carbônico na atmosfera, a fim de que os mesmo providenciassem sua redução, para arrefecer os danos causadores do efeito estufa, prestigiando o princípio da cooperação entre os povos, já que o tema é de interesse comum da comunidade internacional.

Santos (2004) preleciona que 178 países aderiram aos termos do protocolo de Kyoto, cuja meta seria reduzir as emissões de dióxido de carbono em 5,2\% até o ano de 2012. Todavia, importantes países emissores de gás carbônico se negaram a subscrever o documento, a exemplo dos Estados Unidos, sob a alegação de que a ação subscritora traria prejuízos ao crescimento econômico dos países.

Diante dessa breve explanação, tem-se a figuração de alguns exemplos, a partir de tratados e convenções internacionais, tendentes à tutela do meio ambiente. A partir dos inúmeros desastres naturais, além da escassez de recursos naturais, decorrentes da saturação do meio ambiente ante a interferência nociva do homem, a 
sociedade em geral começou a advogar em favor do meio ambiente, o que já demonstra considerável avanço nas questões afetas à natureza.

\section{Entraves e dificuldades à proteção ambiental}

Os Estados nacionais detém a ciência necessária e suficiente acerca dos problemas oriundos dos nefastos e variados impactos ambientais, sendo eles conscientes da premente necessidade de assegurar a proteção do meio ambiente. Todavia, problemas de raiz econômica e política são protuberantes ao surgimento de empecilhos à escorreita aplicação das leis e tratados tendentes à tutela da natureza. Noutra banda, a dificuldade na alocação de recursos públicos com o fito de viabilizar a proteção ambiental é um óbice constante, haja vista a famigerada alegação de ausência de recursos públicos suficientes ao atendimento das demandas de natureza ambiental.

Cavalcanti (2004) salienta a falta de interesse por parte do Brasil, na medida em que há um descompasso tremendo entre a conjugação dos pilares do crescimento econômico e do equilíbrio socioambiental, não obstante que ambos indicadores favorecem 0 desenvolvimento do país. Todavia, devese destacar que a utilização desenfreada dos recursos naturais poderá levar o Brasil a uma grande convulsão ambiental, capaz de afetar drasticamente as futuras gerações.

Para Sousa (2011), os países desenvolvidos semeiam a famigerada cultura da reificação humana, que é a exploração do homem pelo homem, além da exploração indiscriminada da natureza, acarretando um desenvolvimento às avessas, na medida em que os indicadores econômicos estarão em patamares satisfatórios, todavia, benefícios de cunho ambiental, social e cultural assentam-se em indicadores não tão bem posicionados como os índices econômicos.

\begin{abstract}
É preciso trazer a tona e programar o conceito de um desenvolvimento sustentável, calcado no crescimento econômico, conjugando-o com os avanços sociais e culturais, além de mecanismos de conservação da natureza.
\end{abstract}

Friedman (2008) aborda outro problema, que diz respeito às aparências. Para o autor, países que assumem uma bandeira ambientalista apenas em proselitismos e discussões sofistas, mas omissos e escusos na criação de normas jurídicas ambientais e na implementação de ferramentas capazes de assegurar a fiscalização destas, oferecem um grande risco à cadeia ambiental internacional.

No Brasil, recentemente, entrou em vigor o novo Código Florestal, por força da Lei no 12.651/2012, bastante questionável em diversos tópicos. Dentre as alterações legislativas, destaque-se à fixação das Áreas de Preservação Permanente (APP), cujos embates foram travados entre ambientalistas e o setor ruralista, este que através de pressões junto aos congressistas, conseguiu a aprovação almejada que os beneficiaram. Segundo Trindade (2010), o maniqueísmo reservado às discussões, aliado à falta de conhecimentos técnicos dominaram todas as discussões atinentes às modificações do Código Florestal, de sorte que a vitória do setor ruralista pôs em ameaça o pretendido equilíbrio ambiental, além de inviabilizar a própria atividade agropecuária para o futuro, bem como comprometer as gerações vindouras.

Apesar de tudo, o novel diploma florestal procurou identificar as necessidades e ferramentas tendentes à preservação ambiental e um melhoramento da qualidade de vida presente e futura, visando subsidiar meios referentes ao nível de qualidade da produção das terras, considerando as especificidades das regiões e localidades brasileiras (Garcia, 2012).

Deste modo, tem-se que o Direito Ambiental reclama por uma efetiva e ostensiva proteção do meio ambiente, 
almejando a desagregação de eventual conceito figurativo perante o Estado, que segundo Canotilho (2010), trata-se de forma simbólica assumida pelo poder público, que acarreta diversos prejuízos à sociedade, na medida em que oferece uma fictícia realidade de proteção ecológica, por parte de um Estado omisso e sem as ferramentas de controle necessárias ao fomento da tutela ambiental.

Portanto, os problemas ora debruçados comprometem a efetiva proteção ambiental, que carece de maiores aprofundamentos científicos em Pesquisa e Desenvolvimento, capaz de mitigar eventuais danos ambientais e descompassos com os princípios e ditames relativos ao Desenvolvimento Sustentável.

\section{Conclusão}

A conciliação entre os interesses oriundos do crescimento econômico e da proteção ambiental se caracteriza como um elevado desafio assumido pela sociedade hodierna, de modo que a tutela de ambos os interesses é legítima, haja vista que a ausência de desenvolvimento acarreta a estagnação socioeconômica da sociedade, bem como a falta de proteção ambiental ocasionaria diversos problemas à saúde dos homens e dos demais seres vivos, além de impelir a escassez de recursos naturais vitais, a exemplo da água.

A positivação constitucional de norma ambiental é um fenômeno jurídico que acarreta maior segurança jurídica à tutela ambiental, tendo em vista que a Constituição da República, no cerne da hierarquia das leis, assume privilegiada posição no ápice piramidal, de sorte que o meio ambiente recebe proteção por meio de ações judiciais e tantas outras intervenções legitimadas pelo Texto Maior.

Os tratados e r convenções
$\begin{array}{llr}\text { internacionais } & \text { assumem elevada } \\ \text { importância na objetividade das }\end{array}$

questões ambientais, tendo em vista que apesar de não possuir periodicidade permanente, admitem a discussão de problemas em níveis globais, servindo de alerta para que diversos países possam se aliar para o combate das inúmeras questões relativas ao meio ambiente, de sorte que, mesmo nas dissidências e contraposições assumidas por alguns países, as questões são debatidas e tolhidas pela comunidade internacional.

Todavia, a aquisição de uma consciência ecológica é vital para o aprimoramento do desenvolvimento sustentável, calcado na conjugação e conciliação dos interesses econômicos e da preservação ambiental. Desse modo, o avanço tecnológico acarretará novas soluções para velhos problemas, restando a necessidade de investir-se em pesquisa e desenvolvimento, principalmente no enfrentamento das questões energéticas.

A Educação Ambiental deve ser alcançada dos mais longínquos bancos da educação infantil até a plena formação humana e profissional do indivíduo, para que o mesmo possa agregar os valores inerentes ao desenvolvimento sustentável, de modo que a aplicação das leis e a efetivação da punição daqueles que a desatendem, é uma ferramenta pedagógica de auxílio à conscientização ecológica.

Por fim, não obstante a diversidade de leis nacionais $e$ internacionais que regem a matéria ambiental, depreende-se ainda um flagrante desrespeito à sua estrutura normativa, o que atrai profundos dissabores e desequilíbrios para o meio ambiente, que associado à ideia de impunidade, poderá acarretar na perpetuação de condutas nocivas ao meio ambiente.

\section{Conflito de interesses}

Os autores declaram não haver conflito de interesses. 


\section{Referências}

Benjamim, A. H. Direito Constitucional Ambiental Brasileiro. In: Canotilho, J. J. G.; Leite, J.R. M. Direito Constitucional Ambiental Brasileiro. 3. ed. São Paulo: Saraiva, 2010.

Canotilho, J. J. G.; Leite, J. R. M. Direito Constitucional Ambiental Brasileiro. 3. ed. São Paulo: Saraiva, 2010.

Cavalcanti, C. Desenvolvimento sustentável e gestão dos recursos naturais: referências conceptuais e de política. Serra: Arcelor, 2004. (Programa de Comunicação Ambiental, Companhia Siderúrgica de Tubarão).

Diniz, D.; Guilhem, D. 0 que é bioética. São Paulo: Brasiliense, 2002.

Friedman, T. L. Quente, plano e lotado: os desafios e oportunidades de um novo mundo. Rio de Janeiro: Objetiva, 2008.

Garcia, Y. M. O código florestal brasileiro e suas alterações no Congresso Nacional. GeoAtos: Revista Geografia em Atos, n. 12, 2012.

Le Preste, P. Ecopolítica internacional. 2. ed. São Paulo: SENAC, 2005.

Santos, F. P. Meio ambiente e poluição. 2004. Disponível em: <http://jus.com.br/ artigos/4753/meio-ambiente-e-poluicao>.

Acesso em: 12 jun. 2018.
Sarlet, I. W.; Fenterseifer, T. Direito constitucional ambiental: estudos sobre a constituição, os direitos fundamentais e a proteção do ambiente. São Paulo: Revista dos Tribunais, 2011.

Souza, M. M. Dificuldade de preservação e desenvolvimento econômico. 2011. Disponível em: <http://www.webartigos. com/artigos/dificuldade-de-preservacao-edesenvolvimento-economico/57964/>. Acesso em: 18 jun. 2018.

Souza, P. V. S. 0 meio ambiente (natural) como sujeito passivo dos crimes ambientais. Revista Brasileira de Ciências Criminais, n. 50, 2004.

Thomé, R. Manual de Direito Ambiental: conforme o novo código florestal e a Lei Complementar 140/2011. 2. ed. Salvador: Juspodivm, 2012.

WWF Brasil. O que é camada de ozônio? Disponível em: <http://www.wwf.org.br/ natureza_brasileira/questoes_ambientais/ca mada_ozonio/>. Acesso em: 25 jun. 2018.

Informação da Licença: Este é um artigo Open Access distribuído sob os termos da Licença Creative Commons Attribution, que permite uso irrestrito, distribuição e reprodução em qualquer meio, desde que a obra original seja devidamente citada. 